\title{
Factors Affecting Empathy with Patient among Healthcare Provider Students: A Structural Equation Modeling Study
}

\author{
Fatemeh Zahra Karimi ${ }^{1}$, Mahbubeh Abdollahi ${ }^{2}$
}

\begin{abstract}
Context: In medicine and health care, empathy is a very important component of relationship between a physician or healthcare provider and patients.

Aims: This study was designed to investigate the factors affecting empathy with patient among healthcare provider students using structural equation model.

Settings and design: Cross-sectional study

Materials and Methods: It was a cross-sectional study to examine the conceptual model based on JSE-HPS. Three hundred ninety-eight students of School of Nursing and Midwifery, Mashhad University of Medical Sciences, Iran participated in the study. They were selected by quota-stratified sampling. The data were collected by JSE-HPS.

Statistical analysis used: To examine the conceptual model, and SEM was used for ordinal data using WLSMV in Mplus 6.

Results: Findings indicated proper model fit so that "perspective-taking" had a positive effect on "compassionate care". "Compassionate care" had a positive effect on "standing in patient's shoes".

Conclusion: The results of this study can improve students' empathic relationships with patients. The "perspective-taking","compassionate care" and "standing in patient's shoes" must be emphasized in training programs for medical students providing healthcare in order to familiarize them with the importance of empathy and its role in care.

Keywords: Empathic perspective, Empathy, Structural equation modeling

Key messages: Empathy is truly the heart of the relationship, Perspective-Taking, Compassionate Care, and Standing in Patient's Shoes can be taken into account to improve the empathy and establish empathic relationships with patients. Proper environment is expected for improving the disease consequences by establishing empathic relationships.

Indian Journal of Critical Care Medicine (2019): 10.5005/jp-journals-10071-23232
\end{abstract}

\section{INTRODUCTION}

Empathy is the ability to stand in one's shoes to better understand the emotions and experiences during an interaction. ${ }^{1}$ Empathy is the most effective component of an effective communication. In communicating with others, empathizing plays a very effective and accelerating role. Empathy, in fact, prepares shortcuts for communication with others. Additionally, it improves the quality of relationships. ${ }^{2,3}$ Empathy is a very important topic in medicine and health profession and is considered as a very important component of the relationship between the physicians or healthcare providers and patients. Empathizing with patients means realizing their condition, emotions, and feelings in order to provide an effective and quality care. An advantage of empathy is increasing the quality of care and solving the patients' problems. ${ }^{4,5}$

Studies have shown that empathy with patients can increase professional satisfaction, sense of success, improve management of patient, and physicians' accuracy and clinical competence. Empathic relationships can also act as barrier against job stress. 3,5,6 The American College of Medical Education Association has recently proposed that the universities of medical sciences must train healthcare students in a way to enhance empathy and pay a serious attention to patients perspectives, their emotions, social, economic, cultural, and religious background, and their languages. ${ }^{7}$ This is mainly because an empathic relationship between the therapist
${ }^{1}$ Nursing and Midwifery Care Research Center, Mashhad University of Medical Sciences, Mashhad, Iran; Department of Midwifery, School of Nursing and Midwifery, Mashhad University of Medical Sciences, Mashhad, Iran

${ }^{2}$ Department of Public Health, Torbat Heydarieh University of Medical Sciences, Torbat Heydarieh, Iran

Corresponding Author: Mahbubeh Abdollahi, Department of Public Health, Torbat Heydarieh University of Medical Sciences, Torbat Heydarieh, Iran, e-mail: karimifz@mums.ac.ir

How to cite this article: Karimi FZ, Abdollahi M. Factors Affecting Empathy with Patient among Healthcare Provider Students: A Structural Equation Modeling Study. Indian J Crit Care Med 2019;23(9):396399.

Source of support: Nil

Conflict of interest: None

and patients leads to positive therapeutic results. Such relationship also increases the students compatibility and affects their ethical emotions. Therefore, students need to know about their own attitudes, feelings, and behaviours with others before entering work environment. ${ }^{8}$ Studying effective factors in establishing empathy with patients is an important step to identify some of students needs and correctly respond to the needs. A structural equation modeling 
study (SEM) refers to a family of strong statistical processes used by human science researchers to examine the complex relationships among human variables. ${ }^{9}$ The technique is of great importance in human and health science studies since most researchers in this field examine the relationships among various variables within a model or a network of relationships. Therefore, the researchers design a prefabricated model based on the hypotheses on the relationships among variables. Here, the researchers are exposed to a fundamental question: Is the model structure supported by data in real conditions or not? Using SEM and software packages, the researchers are able to find the responses. ${ }^{10,11}$

The aim of this study was investigating the effective factors on establishing empathy with patients among the students of Mashhad School of Nursing and Midwifery, Mashhad, Iran. Fields et al (2011), designed the English version of the Jefferson scale of physician empathy-health care provider student version (JSE-HPS) to evaluate the empathy with patients by health care provider students. The questionnaire has three scales with 20 items. The subscales are perspective-taking, compassionate care, and standing in patient's shoes. ${ }^{12}$ As a result, the model is based on the study by Fields et al. (2011) in terms of empathy with patients consisting of these three subscales and the relationships among them (Fig. 1).

\section{Materials and Methods}

This was a cross-sectional study in 2015 and was approved by the ethics committee of of Mashhad University of Medical Sciences. The hypotheses of the model are as follows:

- Is "perspective-taking" effective in "compassionate care"? What is the extent of the effect?

- Is "compassionate care" effective in "standing in patient's shoes"? What is the extent of the effect?

The statistical population consisted of all students of School of Nursing and Midwifery, Mashhad University of Medical Sciences, Iran. The participants were selected by quota-stratified sampling. The courses of school of nursing and midwifery were considered as stratifies. The share of each course was determined based on the whole population. The data were collected by two questionnaires: (1) demographic questionnaire and (2) Persian version of the JSEHPS. Informed consents were taken from the participants and the goals were also explained.

The JSE-HPS was taken from the Jefferson Scale of Physician Empathy (JSPE) consisting of 20 items. The items are scored on a 1 to 7 Likert scale, each answered on a 7-point Likert scale ranging from $1=$ Strongly disagree to $7=$ Strongly agree. The questionnaire has 10 negative items that are scored in a reverse order. Therefore, each item is scored based on a 7-point-Likert scale. The total scores ranges between 20 and 140. A higher score indicates a higher degree of empathic orientation and students' tendency toward empathic participation in care. The questionnaire has three subscales: perspective-taking, compassionate care, and standing in patient's shoes. Note that the study by Karimi et al. verified the reliability and 3-factor structure of the Persian JSE-HPS version. ${ }^{13}$

The aim of this study was to investigate the conceptual model and carry out the hypothesis testing using SEM for empathy factors,

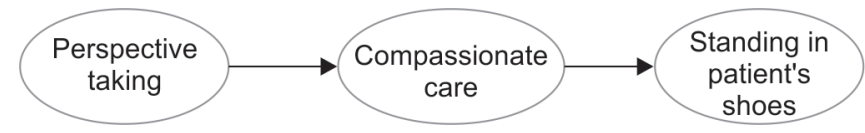

Fig. 1: Research conceptual model introduced by Fields et al. (2011), ${ }^{12}$ SEM is based on factor and path analysis. ${ }^{14}$ It is a method to estimate the unobservable latent variables from the observed indicator variable. The main goal in SEM is to estimate the relationship between latent variables. ${ }^{15,16}$ A latent variable is the one which cannot be directly measured by the researcher and the researchers are only able to have access to the indicators of a latent variable which can be directly measured. ${ }^{14}$ Every SEM is made up of two models: measurement and structural. In the measurement model, the relationship between the indicators and latent factor is studied. In SEM, measurement model is, in fact, a confirmatory factor analysis model to mainly examine the extent to which indicators are able to measure the related latent factor. In the structural model, the direction and extent of relationship among the factors is measured. SEM is a model based on a theory. In other words, the conceptual model is determined based on theory and researcher's experience prior to the analysis. ${ }^{17}$

In this study, the conceptual model is designed based on the study by Fields et al. (2011) $)^{12}$ (Fig. 1).

Depending on the nature of data, various methods are used in SEM to estimate the variance-covariance matrix and model parameters. ML, ${ }^{a} M^{2}{ }^{b}{ }^{b}$ and $M L M V$ were introduced for quantitative data scale and WLS, ${ }^{d}$ WLSM ${ }^{e}$ and WLSMV $^{\mathrm{f}}$ were introduced for ordinal data. In this study, considering the ordinal scale for the data, WLS, WLSM, and WLSMV were used in SEM and Mplus 6 for examining the conceptual model (Fig. 1) in 3-factor model of JSE-HPS. RMSEA, ${ }^{9}$ Chi-square, and corresponding degree of freedom, CFI, ${ }^{\text {h }}$ and $\mathrm{TLI}^{\mathrm{i}}$ were used for model fitting. ${ }^{18}$

Note that RMSEA $\leq 0.06$ shows good fitting, $0.06 \leq$ RMSEA $\leq 0.08$ shows appropriate fitting, $0.08 \leq$ RMSEA $\leq 0.1$ indicates medium fitting and RMSEA $>0.1$ is a weak fitting. $X^{2} / d f<5$ and $X^{2} /$ $\mathrm{df}<3$ show acceptable and good model fitting. If TLI and CFI are greater than 0.90 , the fitting is acceptable. ${ }^{19}$ In each model, if factor loading $\geq 0.4$, it means that the factor is significant in its subscale. ${ }^{20}$

\section{Results}

A total of 398 students of Mashhad School of Nursing and Midwifery participated in the study. Sixty-nine questionnaires were excluded. Finally, 329 questionnaires were analyzed. The mean age of the subjects was $21.59 \pm 3.67$. The mean overall score of students' empathy was 78.22 \pm 9.34 . The mean scores of Perspective-Taking, Compassionate Care and Standing in Patient's Shoes subscales were $40 \pm 6.08,31.26 \pm 4.12$ and $6.96 \pm 1.66$, respectively.

To examine the conceptual model fitting, three methods (WLS, WLSM, and WLSMV) were used assuming ordinal data scale. Since the model did not converge in WLS, only the results of WLSM and WLSMV were reported. The results of conceptual model indices using WLSM and WLSMV are reported in Table 1. The results showed that CFI and TLI were close to 1 in WLSMV and RMSEA was less than 0.1. Chi-square/ corresponding degree of freedom ratio was less than 3. The conceptual model had a better fitting by WLSMV than WLSM.

\footnotetext{
a Maximum Likelihood

${ }^{\mathrm{b}}$ Mean-adjusted maximum likelihood

'Mean and variance-adjusted maximum likelihood

dWeighted least square

e Mean-adjusted Weighted least square

${ }^{f}$ Mean and variance -adjusted Weighted least square

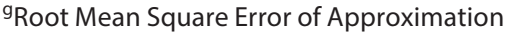

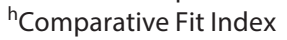

'Tucker-Lewis index
} 
Table 1: Goodness-of-Fit indices for SEM of empathy with patient factors in health service provider students

\begin{tabular}{lllll}
\hline Index & $\mathrm{CFI}^{+}$ & $\mathrm{TLI}^{\ddagger}$ & RMSEA $^{\S}$ & $X^{2} / d f$ \\
\hline WLSM & 0.93 & 0.92 & 0.11 & 5.04 \\
WLSMV & 0.91 & 0.90 & 0.09 & 3.3 \\
\hline
\end{tabular}

† Comparative fit index

¥ Tucker-Lewis index

$\S$ Root mean square error of approximation

Table 2: Standard factor loadings for conceptual model of empathy with patient

\begin{tabular}{|c|c|c|c|}
\hline Subscale & Factor & $\begin{array}{l}\text { Standardized } \\
\text { factor loading }\end{array}$ & R square \\
\hline \multirow[t]{10}{*}{ Perspective taking } & 3 & 0.67 & 0.45 \\
\hline & 4 & 0.76 & 0.58 \\
\hline & 5 & 0.84 & 0.71 \\
\hline & 6 & 0.82 & 0.67 \\
\hline & 8 & 0.73 & 0.53 \\
\hline & 11 & 0.40 & 0.16 \\
\hline & 12 & 0.54 & 0.29 \\
\hline & 13 & 0.58 & 0.34 \\
\hline & 14 & 0.49 & 0.24 \\
\hline & 17 & 0.72 & 0.52 \\
\hline \multirow[t]{8}{*}{ Compassionate care } & 1 & 0.43 & 0.18 \\
\hline & 2 & 0.68 & 0.46 \\
\hline & 7 & 0.81 & 0.66 \\
\hline & 9 & 0.48 & 0.23 \\
\hline & 10 & 0.46 & 0.21 \\
\hline & 15 & 0.54 & 0.29 \\
\hline & 19 & 0.27 & 0.07 \\
\hline & 20 & 0.41 & 0.17 \\
\hline \multirow{2}{*}{$\begin{array}{l}\text { Standing in patient's } \\
\text { shoes }\end{array}$} & 16 & 0.72 & 0.52 \\
\hline & 18 & 0.70 & 0.49 \\
\hline $\begin{array}{l}\text { The effect of per- } \\
\text { spective taking on } \\
\text { compassionate care }\end{array}$ & - & 0.76 & 0.58 \\
\hline $\begin{array}{l}\text { The effect of com- } \\
\text { passionate care on } \\
\text { standing in patient's } \\
\text { shoes }\end{array}$ & - & 0.52 & 0.27 \\
\hline
\end{tabular}

In Table 2, the standard loading factors and squared standard loading factors were reported. The results of Table 2 indicated that all items of Perspective-Taking and Standing in Patient's shoes were significant in its subscale. For this reason, no one was eliminated. But, since the loading factor for Item 19 of Compassionate Care was less than 0.4 , it was not significant. In each subscale, greater loading factor showed that the question was a better indicator for the subscale. The results of Table 2 showed that Questions 3, 4, 5 , 6,8 , and 18 of Perspective-Taking were better indicators for this subscale. For Compassionate Care, Items 2 and 7 were the best

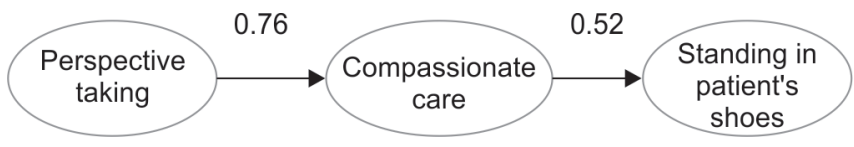

Fig. 2: Standard coefficients of conceptual model of empathy with patient

indices for this subscale. For Standing in Patient's Shoes, both questions 3 and 6 were considered good indices for the subscale.

Perspective-Taking had a positive effect on Compassionate Care, and Compassionate Care had a positive effect on Standing in Patient's Shoes information so that $58 \%$ of Compassionate Care information was determined by Perspective-Taking and $27 \%$ of Standing in Patient's Shoes was determined by Compassionate Care (Fig. 2).

\section{Discussion}

This article aimed at examining the relationships among the effective factors in empathy with patients by healthcare provider students (JSE-HPS). The results showed relationships among Perspective-Taking, Compassionate Care, and Standing in Patient's Shoes. The empathy with patients by student healthcare provider is determined by these three factors so that standing in Patient's Shoes was determined by the Compassionate Care and the latter was determined by Perspective-Taking. Indeed, students need to look at different issues from the perspective of patients and understand their emotional status in order to be able to establish an empathic relationship, imagine themselves in their shoes, and understands their feeling. In other words, empathy is a process which includes the entry to one's world and understands his/her experiences, concerns, and responds to the needs. ${ }^{8,21,22}$ Today, empathy is accepted as the basis of relationships with patients and it is an essential component among health professionals. Health students need to be trained in a way to establish an empathic relationship with their patients., ${ }^{7,23}$

Patients communicate better with the healthcare providers if empathized. This is associated with the fact that when we do not realize others, we have no way of communicating.

Empathy also helps understanding one's current behaviors and forecast the behaviors while dealing with. When someone empathizes, he listens better and has a better understanding of the problem, responds more completely and accurately and facilitate problem-solving process, and prevents harms. Empathy increases the quality of relationships and satisfaction. ${ }^{4,5}$

Empathy is considered an important topic in modern moral philosophy and it plays a key role in moral and social development. ${ }^{2,3}$

Studies have also shown that empathic relationship between the health provider and patient not only improves the patient's experience as the care recipient but also leads to positive care and therapeutic results. ${ }^{8,22}$ So that, if there is no empathy during the care or the quality of empathy is poor, several problems are expected such as problems in diagnosis, lack of proper use of medication, lack of follow-up therapy, wasting time for doctors and patients, and waste of expenses and in certain cases, it contributed to death. Therefore, empathy can have a direct effect in patients' clinical consequences. ${ }^{22}$ Therefore, empathy, as one of human dimensions of care, is essential to ensure a quality relationship between health care provider and patient. That is why it is accepted as the basis of communication with patients. ${ }^{4,5}$ Since healthcare students are in charge of future health system and empathy is an important part 
of communication process in medicals science, evaluating, training, and empowering students is of great importance in this regard.

According to the results of this study, Perspective-Taking, Compassionate Care, and Standing in Patient's Shoes can be taken into account to improve the empathy and establish empathic relationships with patients. Thus, it is recommended to do more studies on the relationship of these factors and their roles in therapeutic results and factor strengthening them. A strong point of the study was that it was the first study to examine the factors affecting the empathy with patients among healthcare provider students. Trust in responses of the subjects was a limitation in this study. The subjects were provided with explanations to win their trust. Since the study was conducted among the students of School of Nursing and Midwifery in Mashhad University of Medical Sciences, it is recommended to study the same topic in other universities of medical sciences in order to generalize the results.

The results of this study can help improve students' empathic relationships and it is essential to emphasize more on the Perspective-Taking, Compassionate Care, and Standing in Patient's Shoes to familiarize the healthcare provider students with the importance of empathy and its role in care. Proper environment is expected for improving the disease consequences by establishing empathic relationships.

\section{Acknowledgments}

This study was extracted from the project approved by Mashhad University of Medical Sciences. Hereby, the research deputy of the university is sincerely appreciated and our thanks also go to the Professor Mohammad Reza Hojjat and Dr Seyyed Vahid Shariat for their cooperation and valuable guidance.

\section{References}

1. Hojat M. Empathy in patient care: antecedents, development, measurement, and outcomes: Springer Science \& Business Media; 2007.

2. MR, RS. Empathy, the most effective. Tehran: Ghatre Publishing; 2011.

3. Khodabakhsh MR, Mansoori P. Empathy and its impact on promoting physician-patients relationship. Iranian Journal of Medical Ethics and History of Medicine. 2011; 4(3):38-46.

4. Williams B, Boyle M, Brightwell R, Devenish S, Hartley P, McCall M, et al. An assessment of undergraduate paramedic students' empathy levels. International Journal of Medical Education. 2012; 3:98-102.

5. Ozcan C, Oflaz F, Sutcu Cicek H. Empathy: the effects of undergraduate nursing education in Turkey. International Nursing Review. 2010; 57(4):493-499.

6. Ozcan C, Oflaz F, Bakir B. The effect of a structured empathy course on the students of a medical and a nursing school. International nursing review. 2012; 59(4):532-538.
7. Jabarifar S, Khalifesoltani F, Nilchian F, Yousefi A, Hoseinpour K Empathy levels in undergraduate and postgraduate dental students in Isfahan Faculty of Dentistry in 2011. J Isfahan Dent Sch. 2012; 7(5):753-762.

8. Ashghali Farahani M, Salehi T, Arab Ameri Z, Hajibabaee F, Hosseini AF, Ghaffari F. Empathy among undergraduate nursing students in Tehran University of Medical Sciences. Iranian Journal of Medical Ethics and History of Medicine. 2016;9(4):56-67.

9. Alavi M. Reporting the results of structural equation modeling (SEM) writing. Quarterly Journal of Nursing Management. 2014; 3(2):8-19.

10. Alavi M. Structural equation modeling (SEM) in health sciences education researches: an overview of the method and its application. Iranian Journal of Medical Education. 2013; 13(6):519-530.

11. Adelson JL. Examining relationships and effects in gifted education research: An introduction to structural equation modeling. Gifted Child Quarterly. 2012; 56(1):47-55.

12. Fields SK, Mahan P, Tillman P, Harris J, Maxwell K, Hojat M. Measuring empathy in healthcare profession students using the Jefferson Scale of Physician Empathy: health provider-student version. Journal of interprofessional care. 2011; 25(4):287-293.

13. Karimi FZ, Zarifnejad G, Abdolahi M, Ali Taghipour A. Surveying the factor structure and reliability of the Persian version of the Jefferson scale of physician empathy-health care provider student version (JSEHPS). Hayat. 2015; 21(3):5-14.

14. Wang J, Wang $X$. Structural equation modeling: Applications using Mplus: John Wiley \& Sons; 2012.

15. Equacions Estructurals Bollen K. Structural Equations with Latent Variables. New York: John Wiley \& Sons, Inc. Wiley, DE (1973) The Identification Problem for Structural Equation Models with Unmeasured Variables in Goldberger AS and Duncan, OD eds. Tructural Equation Models in the Social Sciences-New York: Academic Press; 1989.

16. Joreskog KG, Sorbom D, Magidson J. Advances in factor analysis and structural equation models. 1979.

17. Ho R. Handbook of univariate and multivariate data analysis and interpretation with SPSS: CRC Press; 2006.

18. Tabachnick BG, Fidell LS, Osterlind SJ. Using multivariate statistics. 2001.

19. Byrne BM. Structural equation modeling with LISREL, PRELIS, and SIMPLIS: Basic concepts, applications, and programming: Psychology Press; 2013.

20. Hulland J. Use of partial least squares (PLS) in strategic management research: A review of four recent studies. Strategic management journal. 1999:195-204.

21. Naeini NE. Empathy. Tehran: Honar Abi; 2010.

22. Managheb E, Bagheri S. The Impact of Empathy Training Workshops on Empathic Practice of Family Physicians of Jahrom University of Medical Sciences. Iranian Journal of Medical Education. 2013; 13(2):114-122.

23. Dehning S, Girma E, Gasperi S, Meyer S, Tesfaye M, Siebeck M. Comparative cross-sectional study of empathy among first year and final year medical students in Jimma University, Ethiopia: Steady state of the heart and opening of the eyes. BMC Medical Education. 2012; 12(1):34. 